\title{
RESEARCH AND PRACTICE OF THE NEWS MAP COMPILATION SERVICE
}

\author{
ZHAO Tingting ${ }^{1 *}$, LIU Wanzeng ${ }^{1}$, MA Wei ${ }^{2}$ \\ ${ }^{1}$ National Geomatics Center of China, Beijing 100830, China \\ ${ }^{2}$ National Quality Inspection and Testing Center for Surveying and Mapping Products, Beijing 100830, China
}

KEY WORDS: News Map, Map Compilation, Service, News Base Map, Hot News Thematic Map

\begin{abstract}
:
Based on the needs of the news media on the map, this paper researches on the news map compilation service, conducts demand research on the service of compiling news maps, designs and compiles the public authority base map suitable for media publication, and constructs the news base map material library. It studies the compilation of domestic and international news maps with timeliness and strong pertinence and cross-regional characteristics, constructs the hot news thematic gallery and news map customization services, conducts research on types of news maps, establish closer liaison and cooperation methods with news media, and guides news media to use correct maps. Through the practice of the news map compilation service, this paper lists two cases of news map preparation services used by different media, compares and analyses cases, summarizes the research situation of news map compilation service, and at the same time puts forward outstanding problems and development suggestions in the service of news map compilation service.
\end{abstract}

\section{INTRODUCTION}

As a key product of surveying and mapping geographic information public services, news map is the most intuitive reflections of surveying and mapping geographic information achievements. It can serve the relevant departments of news media and provide standard map services for standardizing the use of news media maps. The news map is a kind of thematic map with news as its essentials. All location-related news can be made into news maps by spatially processing its news content, obtaining location information, and then combining the base map.

The spatial expression of traditional news is usually implicit, and when the spatial elements of news are expressed in the form of a map, a news map of graphic form is formed, which facilitates the visualization of the news. Therefore, the map is a good information carrier and communication tool for the news media. However, since the maps usually bear the peculiarities of propagating national sovereignty, the maps on the Internet are mixed with each other, the news media can hardly find the maps that meet the requirements to represent the news events, the frequent occurrence of unqualified map events, the use of maps by some media, and even some mistakes have occurred. Based on the needs of the news media on the map, this paper studies the use of flexible mechanisms to compile the news base map available to the news media, compiles and provides standard map products and services, and guides the news media to use the map by establishing closer contact and cooperation with the news media, The map as a carrier to express news events can further promote the public's cognition of the news map, realize the spatialization of news events, guide the public's geographical thinking and news space imagination, and serve the media publicity.

\section{NEWS MAP COMPILATION SERVICE RESEARCH}

First, several mainstream news media with their own characteristics are contacted to conduct research on the requirements of news map compilation service, and conduct statistical analysis on the standard map services on the website of the National Bureau of Surveying, Mapping, and Mapping, and to determine the size, type, expression, etc. of news map. Then, on the basis of research and analysis, develop the overall design, design and prepare the news base diagram, build the news base map material library, combine news hotspots, carry out hot news collection and analysis work, and compile hot news topics maps according to actual needs; aiming at news media's demand for geographic information, rapidly produce standardized news thematic maps, provide news map customization services, finally, news maps are promoted and used in conjunction with relevant news media organizations. The overall technological process of news map compilation service is shown in Figure 1. 


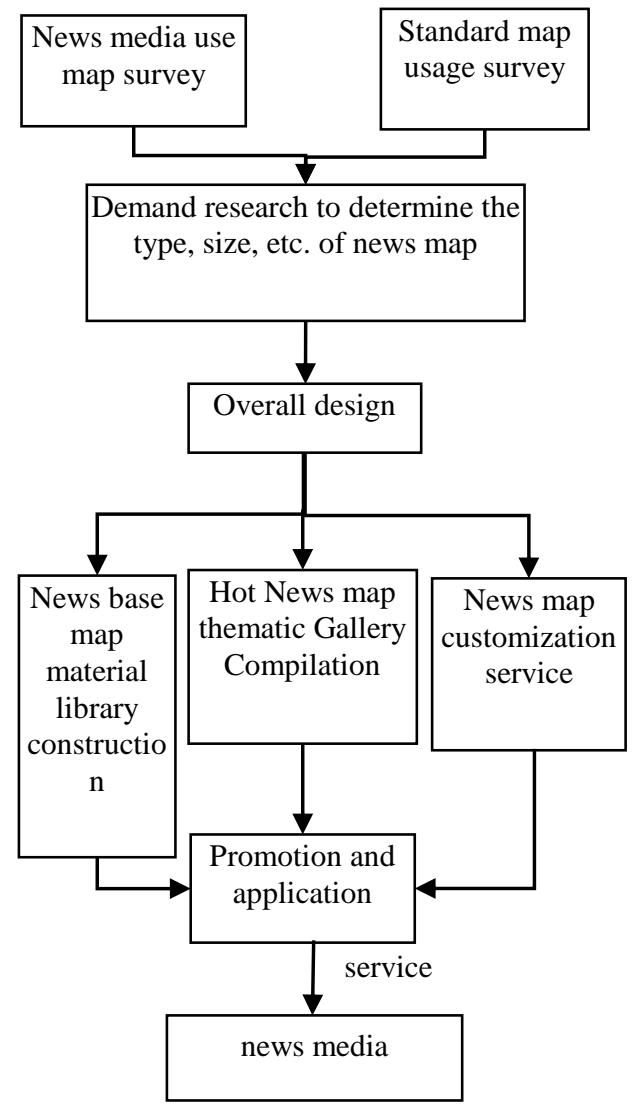

Figure 1. News map compilation service research overall technical flow chart

\subsection{The News Base Map Material Library Construction}

Due to the special needs of news maps, research work is very important. According to different types of media, the survey work objects are divided into three major categories: television media, news agencies and paper media, and online media. Among them, the television media includes authoritative TV stations such as CCTV and Beijing Satellite TV. The news agencies and paper media include the central news media such as People's Daily, Xinhua News Agency, Guangming Daily, and Economic Daily. The online media includes Xinhua, People's Daily, and Bright Online. The research work is divided into three steps: the first step is to formulate the questionnaire according to the characteristics of the media; the second step is to organize the media graphics departments to answer the questionnaires and provide opinions and suggestions for the hot news thematic maps; the third step is to invite the relevant experts to conduct an analysis of the questionnaire and the proposed content, summarizing the different needs of different types of media for news maps.

Based on the use of map research results by the news media, it analyzes and sums up the different needs of various media for news maps, designs the public authority base map suitable for media publication and constructs the news base map material library. Schematic type of news base map types include administrative maps, topographic maps and thematic maps, including various forms of maps, and finally pictures, vectors and other forms provided to the news media as a base map for the compilation of news maps. The map area is mainly within the map of the administrative divisions, does not involve crossregional scope.

The news base map of the news bulletin is the base map of the news events. Based on the overall design and the base style of the requirements research, the relevant data from the national basic geographic information database are extracted according to the style, and the base map elements, expressions, layouts, and layouts are designed. Scope and make a sample, each basemap consists of a theme of four factors. Finally, the sample parameters are imported into the system, and the map is compiled, and the news base map material library is finally formed.

\subsection{Hot News Thematic Map Compilation}

Combining the major national strategic plans, important current affairs news, social concerns and media needs, this paper studies the compilation of domestic and international news maps with timeliness and strong pertinence and cross-regional characteristics, and constructs the hot news thematic gallery. The hot news thematic map can be used as the base map of news or released directly for use. It is a news map that is urgently needed by the news media. It is a news map of hot spots both at home and abroad and is timely promoted and released and used by various news media.

Jointly related media organizations, in conjunction with the latest national strategic planning, current news and media needs, proposed the preparation of topics (such as the Belt and Road, Beijing-Tianjin-Hebei integration, the Yangtze River Delta, and two sessions, etc.) and collect relevant hot news materials from established the material bank and the existing surveying and mapping achievements data are used to obtain the relevant elements of the topic selection, spatially processing the hot topic topics, or spatially associating with the surveying and mapping geographic information. After completing the spatialization of news hotspots and preparation of surveying and mapping data, thematic maps of hot news topics will be prepared.

The types of maps included in the maps mainly include vector diagrams, relief maps, and image maps. Vectors need to be reduced, symbolized, and other processing; terrain maps and image maps need to raster data mosaic processing, cropping and other processing, and some of the vector data overlay, after the reduction of the symbolic display.

\subsection{News Map Customization Service}

Faced with the special needs of the news media for news maps, under the circumstances that the existing news base map material library and hot news thematic galleries can not meet the demand, this paper carries out news map custom service research, in a short period of time to make normative news thematic maps for the news media units to publish use.

\subsection{News Map Type}


Due to the particularity of news media demand for maps, news map classification and traditional map classification methods are different. According to different topics, there are different classification methods. This article mainly studies several commonly used news maps. Classified according to the map representation topics, they can be divided into political, economic, nature, environment, weather, advertising and other maps, according to the map than the ruler to classification, they can be divided into large, medium and small scale maps, follow the traditional map division standards. Classified according to the scope of mapping, they can be divided into maps of the world, national level, province, city, county, city, etc.; according to different media, news media communication platform is divided into traditional paper media (news agency and paper media), television media, and online media, according to the demand for news maps in traditional paper media, television media, and online media can be divided into static and dynamic news maps.

Another research focus of this article is to develop static and dynamic news map production service research, innovate the performance of static news maps, and use surveying and mapping geographic information to provide media with Flash, video and other forms of dynamic news maps.

\section{NEWS MAP COMPILATION SERVICE PRACTICE}

Through the practice of compiling news maps, we studied the news map compilation services required by the news media for different media and listed two successful cases.

\subsection{Service Application Case for Traditional Paper Media}

In response to the need for illustrations of newspapers and magazines for the "China Children's Daily", two maps were drafted: "China Folk House Party" and "World Name Building" Lost are published in the "China Children's Daily (FebruaryJanuary 2018 Winter Vacations)" Play Construction Special Issue. "China Folk House Party" uses the map of China's political districts as a base map to mark the location of the six distinctive residences, together with the photos and written descriptions of the residential quarters, briefly introducing the characteristics of the six residential areas. "The world's famous building lost its way" uses the map of the world's administrative districts as its base map. In the form of questioning, the young readers find ten homes for the world's "famous buildings." This type of map allows young readers to learn the knowledge and understand the correct maps, thereby enhancing the national landscape awareness.

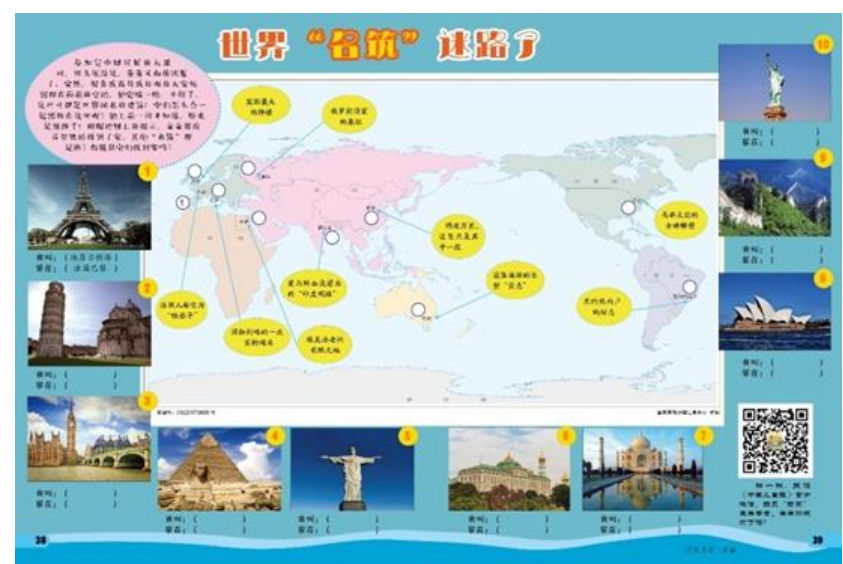

Figure 2. The world's "building" lost its way

\subsection{Service Application Case for Network Media}

The joint Xinhua News Agency jointly launched a multimedia news report "Let's see and read the map of Secretary Xi's Spring Festival" and launched it on platforms such as web clients. The map was a dynamic news map presenting and interpreting the situation of Secretary Xi's visit to the grassroots on the eve of the Spring Festival in recent years.

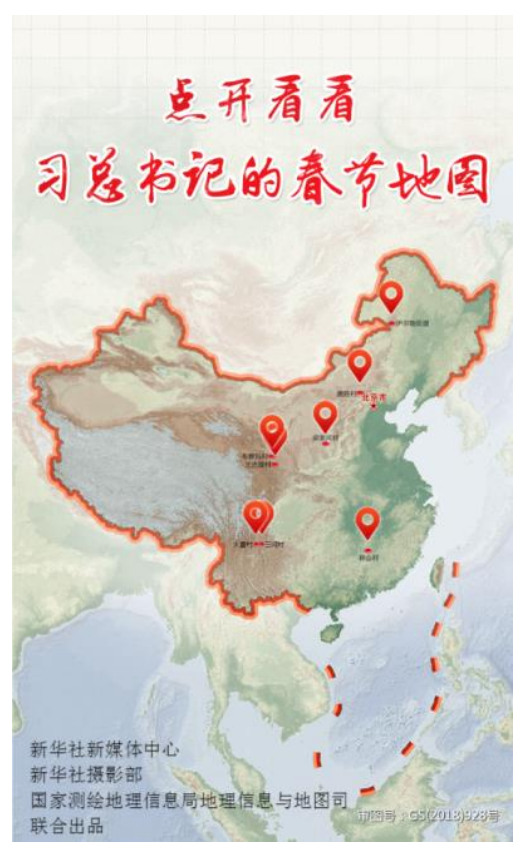

Figure 3. Click to see Xi’s Spring Festival map

\subsection{Comparative analysis of cases}

Comparative analysis of cases, from the use of map types, maps, form, news base maps, hot news thematic maps, news maps, custom services and other aspects of the analysis and research, with the development of the Internet, new media has occupied the main news market The diversity of news media and the complexity of news content have brought challenges to the project in the research and design of standard news maps. It will further summarize the different needs of various types of media 
for news maps and build a full range of news base map material library and hot news thematic map gallery.

\section{CONCLUSIONS}

In short, news happens on a daily basis and is almost always associated with location, so presenting news events in the form of news maps is enduring. The total use of the research results of this paper can provide the news media with a more efficient and authoritative news map service. On the basis of this, a network platform library of news maps will be established to provide the news media with long-term map services, making them accustomed to using maps to express news events, ensuring that correct news maps are accessible to the public and gradually improving the level of mapping and geographic information services. It can promote the social application of basic surveying and mapping products, provide better surveying and mapping guarantees for national economic construction and social development, achieve good social benefits, and have certain sustainable benefits.

\section{ACKNOWLEDGEMENTS}

This work is partly supported by National Key R\&D Program of China (No. 2016YFC0803109) and China Knowledge Center for Engineering Science and Technology Construction Project (No. CKCEST-2017-4-1).

\section{REFERENCES}

Chen, C.F., 2013. Data news and its structure: building schema information - taking the washington post's map news as an example. News and Writing, (08), pp. 92-94.

Cong, Y., 2013. How to use news mapping to improve the "gold content" of a report. News and Writing, (01), pp. 72-75.

Feng, F., and Ai, H.H., 2017. From the digital journalism and the precision journalism to the data journalism. Journalism Evolution, (03), pp. 73-79.

Feng, P.Y., Wu, X.L., and Liu, H.Y., 2016. Fast map maker framework and implementation of hot news events. Journal of Information Engineering University, 17(06), pp. 754-759.

Feng, Z.Q., 1996. On the development of china news map. Cartography, (04), pp. 28-31.

Song, K.J., and Wang, X.L., 2017. How does the data news use maps? - Taking the Guardian, the New York Times, and the Washington Post as examples. Journalism Lover, (04), pp. 2933.

Tang, L., 2013. The release of military news map and research on case retrieval method. Liaoning Technical University, Liaoning, China.

Tang, L., Zhu, Y., Tao, K.W., and Feng, Y., 2013. Implementation of website news map functionbased on map world. Computer Science and Application, 3(06), pp. 282-287.
Xuan, Z.X., 2010. Practice and research on compiling and publishing news map. Beijing Surveying and Mapping, (03), pp. 73-76. 